\title{
Analisis Struktur Gedung Beton Dengan Sistem Pracetak pada Gedung Rusun Joho
}

\author{
Firzil Rohim Ghifari' ${ }^{1)}$ \\ 1) Fakultas Teknik, Program Studi Teknik Sipil, Universitas Veteran Bangun Nusantara, Sukoharjo, Jl. \\ Letjen Sudjono Humardhani, No.1, Jombor, Sukoharjo; Telp. 0271-593156. Email: \\ frohimghifari@gmail.com
}

\begin{abstract}
Abstrak
Rusun Joho merupakan bangunan yang menggunakan struktur beton pracetak, dimana struktur beton dicetak di pabrik khusus pembuatan beton pracetak terlebih dahulu sebelum dipasang di lokasi pembangunan. Untuk mengetahui kuat tahan struktur beton pracetak terhadap gempa digunakan metode ragam spektrum respons. Perhitungan analisis struktur menggunakan software SAP 2000 V14. Hasil analisis tersebut berupa simpangan antar tingkat (displacement) dan base shear. Hasil analisis tersebut digunakan untuk mengontrol kinerja batas layan dan ultimate struktur. Untuk analisis hubungan balok kolom menggunakan SNI 03-2847-2002. Dalam menganalisis hubungan balok kolom pada struktur gedung pracetak tersebut digunakan balok yang menerima momen terbesar dimana data momen tersebut didapat dari hasil output SAP $2000 \mathrm{~V} 14$, dan sebagai sample yang mewakili seluruh hubungan balok kolom gedung Rusun Joho dihasilkan hubungan balok kolom tengah bentang $\phi V c(2975,324)>\mathrm{V}$ $(2954,119)$ (sambungan aman) dan hubungan balok kolom ujung bentang $\phi V c(2975,324)>1559,99$ (sambungan aman).
\end{abstract}

Kata kunci: respons spektrum, kinerja batas layan \& ultimate, analisis hubungan balok kolom

\begin{abstract}
Rusun Joho is a building that uses precast concrete structures, where the concrete structure is printed at a special factory for making precast concrete before being installed at the construction site. To determine the resistance strength of precast concrete structures against earthquakes, various response spectrum methods are used. Structural analysis calculations using SAP 2000 V14 software. The results of the analysis are in the form of deviation between levels (displacement) and base shear. The results of the analysis are used to control the performance of the service limit and ultimate structure. For the beam-column relationship analysis using SNI 03-2847-2002. In analyzing the beam-column relationship in the precast building structure, the beam that receives the greatest moment is used where the moment data is obtained from the SAP 2000 V14 output, and as a sample representing all beam relationships of the Flat Joho building, the beam relationship is the center column-span $\phi V c$ (2975, $324)>V(2954,119)$ (secure connection) and span end column beam connection $\phi V c(2975,324)>1559.99$ (secure connection).
\end{abstract}

Keywords: response spectrum, ultimate \& service limit performance, beam-column relationship analysis.

\section{PENDAHULUAN}

Gempa bumi merupakan getaran yang terjadi pada permukaan tanah yang dapat disebabkan oleh aktivitas tektonik, vulkanisme, longsoran termasuk batu, bahan peledak. Dari semua penyebab tersebut, goncangan yang disebabkan oleh peristiwa tektonik merupakan penyebab utama kerusakan struktur dan perhatian utama dalam kajian tentang bahaya gempa (Chen dan Lui, 2006).

Menurut Daniel L. Schodek (1999), gempa bumi dapat terjadi karena fenomena getaran dengan kejutan pada kerak bumi. Getaran ini nantinya akan menimbulkan gaya-gaya pada struktur bangunan karena struktur bangunan cenderung mempunyai gaya untuk mempertahankan dirinya dari gerakan.

Rumah Susun Joho terletak di Kelurahan Joho, Kecamatan Sukoharjo, Kabupaten Sukoharjo, dan Rumah Susun Joho sebagian besar dihuni oleh karyawan PT. SRITEX, Rumah Susun Joho dibangun pada tahun 2007 yang struktur bangunannya terbentuk dari struktur beton bertulang pracetak atau struktur beton yang dibuat di pabrik khusus pembuatan beton pracetak sebelum dipasang dilokasi pembangunan Rumah Susun Joho, struktur pracetak yang ada pada Rumah Susun Joho yaitu balok pracetak, kolom pracetak dan plat pracetak, bangunan tersebut terdiri dari 4 lantai 
yang terdiri dari lantai dasar, lantai 1, lantai 2, dan lantai 3.

Desain bangunan dengan precast sudah banyak dilalukan di Indonesia (Wahyudi dan Hanggoro, 2010). Dalam menggunakan struktur beton precast sama halnya dengan menggunakan struktur beton konvensional, kita juga perlu mempertimbangkan tingkat keamanan bangunan terhadap Beban Hidup, Beban Mati, Beban Angin, dan beban gempa. Kita dapat menggunakan banyak cara untuk menganalisis beban tersebut salah satunya yaitu menggunakan SAP 2000. Selain itu Suatu struktur harus memiliki kekakuan yang cukup sehingga pergerakkannya dapat dibatasi terutama pada bagian sambungan elemen struktutr (Nurwadji, 2006; Prihatmojo dkk, 2007; Nurjaman dkk, 2010; Kusumawardhana, 2012). Kekakuan struktur dapat diukur dari besarnya simpangan antar lantai. Besarnya perpindahan horizontal pada struktur bangunan gedung (displacement). Menurut McNulty (1956) perpindahan lateral (displacement) pada bangunan gedung adalah $6 \mathrm{~mm}$ lebih dari itu dianggap berbahaya. Karena itu, analisis beban deformasi harus dilakukan guna menentukan besamya beban lateral dan perpindahan lateral yang masih diperbolehkan.

Dalam mendesain suatu sistem struktur beton pracetak, terdapat syarat kekuatan yang harus dipenuhi berdasarkan peraturan yang terkait. Beberapa peraturan yang berlaku di Indonesia yang terkait dengan struktur bangunan, di antaranya adalah Standar Nasional Indonesia (SNI) 03-2847-2002 tentang Tata Cara Perhitungan Struktur Beton untuk Bangunan Gedung, SNI 03-1726-2002 tentang Tata Cara Perencanaan Ketahanan Gempa untuk Bangunan Gedung.

Tujuan dari penelitian ini yaitu menganalisis struktur beton pracetak bangunan rumah susun Joho, menganalisis displacement yang terjadi pada struktur bangunan pracetak pada rumah susun Joho, dan menganalisis tingkat keamanan bangunan beton pracetak rumah susun Joho terhadap gempa.

\section{METODE}

\section{Metode penelitian}

Metode penelitian ini menggunakan analisis struktur beton dengan sistem pracetak. Analisis menggunakan program SAP 2000 V14. Untuk mewujudkan uraian diatas maka langkah analisis yang hendak dilakukan sesuai dengan prosedur.

Pengumpulan data dan informasi bangunan Rumah Susun Joho menggunakan data eksisting. Data yang didapat adalah shop drawing Rumah Susun Joho. Data ini digunakan untuk pemodelan struktur 3D yang selanjutnya dianalisis dengan bantuan SAP 2000 V14.

Menghitung beban-beban yang bekerja pada struktur berupa beban mati, beban hidup. Beban mati yang dihitung berdasarkan pemodelan yang ada dimana beban sendiri didalam program SAP 2000 dimasukan dalam load case DEAD. Beban hidup disesuaikan dengan peraturan yang ada. Perhitungan beban hidup ini dalam program SAP 2000 untuk live adalah 0 , dimana beban hidup perlu dimasukkan secara manual sesuai dengan yang ada.

Dalam tahap analisis semua parameter, baik berupa beban maupun struktur akan diterjemahkan dalam bentuk tiga dimensi pada software SAP 2000 V14. Pada software SAP 2000 V14, kolom dan balok dimodelkan sebagai frame dan plat lantai dimodelkan sebagai shell. SAP 2000 V14 akan menganalisis setiap input yang ada, baik berupa beban dari luar berupa beban lateral dan aksial maupun beban struktur itu sendiri. Kontrol struktur bangunan terhadap gempa menggunakan peraturan menurut SNI 03-1726-2002 dengan metode analisis ragam spektrum respons. SAP 2000 V14 akan mengeluarkan output berupa joint displacement dan base shear.

Analisis sambungan beton pracetak mengacu pada Tata Cara Perhitungan Struktur Beton untuk Bangunan Gedung SNI 03-2847-2002.

\section{HASIL DAN PEMBAHASAN}

\section{Desain Respons Spektrum}

Nilai respons spektrum tersebut harus dikalikan dengan suatu faktor skala yang besarnya $=\mathrm{g}$ x I/R dengan $\mathrm{g}=$ percepatan gravitasi $\left(\mathrm{g}=9,81 \mathrm{~m} / \mathrm{det}^{2}\right)$.

Faktor skala $=9,81 \times 1 / 8,5=1,154117647$

Nilai faktor skala 1,154117647 kemudian digunakan sebagai faktor pengali pada software SAP 2000 seperti pada gambar 1 . 


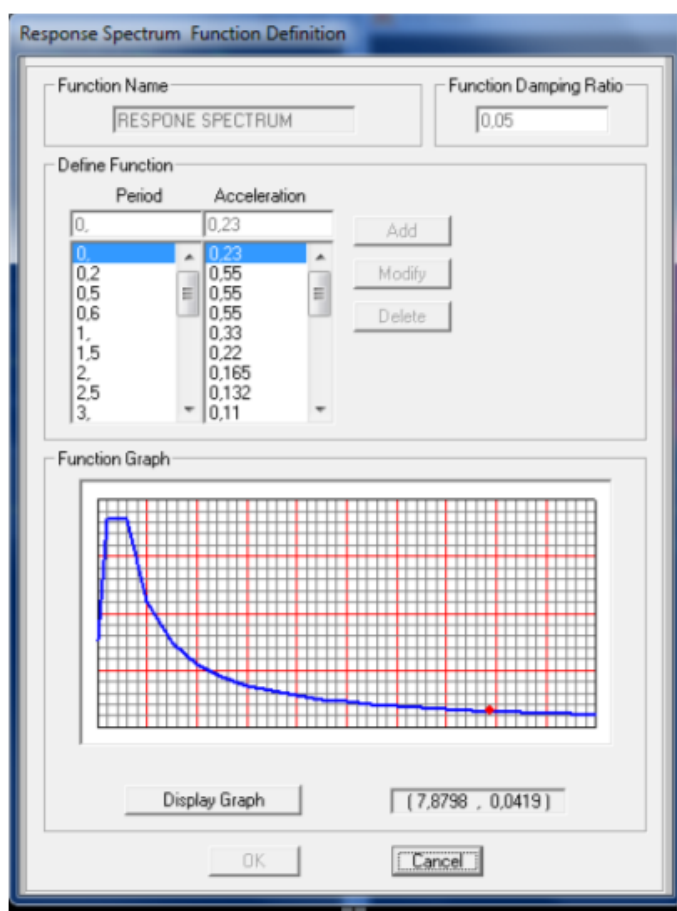

Gambar 1. Desain Respons Spektrum

\section{Kontrol Partisipasi Massa}

Menurut SNI 03-1726-2002, perhitungan ragam spektrum respons struktur harus sedemikian rupa sehingga partisipasi massa dalam menghasilkan respons total harus sekurang-kurangnya $90 \%$.

Tabel 1. Modal Participating Mass Ratio

\begin{tabular}{ccc}
\hline $\begin{array}{c}\text { Periode } \\
\text { Sec }\end{array}$ & $\begin{array}{c}\text { Sumbu x } \\
\text { Unitless }\end{array}$ & $\begin{array}{c}\text { Sumbu y } \\
\text { Unitless }\end{array}$ \\
\hline 0,51803 & $5.82 \mathrm{E}-17$ & 0 \\
\hline 0,406373 & $1.91 \mathrm{E}-16$ & 0 \\
\hline 0,36705 & $1.22 \mathrm{E}-13$ & $1.07 \mathrm{E}-17$ \\
\hline 0,17059 & $1.63 \mathrm{E}-13$ & $2.98 \mathrm{E}-14$ \\
\hline 0,140498 & $6,42 \mathrm{E}-16$ & $1.45 \mathrm{E}-13$ \\
\hline 0,120622 & $5.13 \mathrm{E}-12$ & $2.04 \mathrm{E}-13$ \\
\hline 0,103462 & $3.98 \mathrm{E}-11$ & $2.36 \mathrm{E}-13$ \\
\hline 0,09571 & $5.58 \mathrm{E}-11$ & $4.75 \mathrm{E}-13$ \\
\hline 0,079689 & 0,000104 & 0,0001459 \\
\hline 0,079099 & 0,008878 & 0,02 \\
\hline 0,075575 & 0,071 & 0,079 \\
\hline 0,075413 & 0,912 & 0,895 \\
\hline
\end{tabular}

\section{Kontrol Gaya Geser}

Nilai akhir ragam spektrum respons struktur gedung terhadap pembebanan gempa nominal akibat pengaruh gempa rencana dalam suatu arah tertentu tidak boleh diambil kurang dari $80 \%$ nilai respons ragam pertama.

Kontrol gaya geser arah $\mathrm{x}$ :

$$
\mathrm{V} \geq \quad 0,8 \times \mathrm{V} 1
$$

$76212,96 \geq 0,8 \times 95266,20169$

$76212,97 \geq 76212,96135$ (Memenuhi syarat)

Kontrol gaya geser arah y :

$$
\mathrm{V} \geq \quad 0,8 \times \mathrm{V} 1
$$

$76212,97 \geq 0,8 \times 95266,2017$

$76212,97 \geq 76212,96135$ (Memenuhi syarat)

Tabel 2. Displacement

\begin{tabular}{cccc}
\hline Lantai & Joint & Displacement & Arah \\
\hline $\begin{array}{c}\text { lantai } \\
\text { atap }\end{array}$ & 191 & 0,003598 & $\mathrm{X}$ \\
\hline & 214 & 0,007521 & $\mathrm{Y}$ \\
\hline 3 & 559 & 0,003238 & $\mathrm{X}$ \\
\hline & 585 & 0,006542 & $\mathrm{Y}$ \\
\hline 2 & 265 & 0,002528 & $\mathrm{X}$ \\
\hline & 284 & 0,004986 & $\mathrm{Y}$ \\
\hline 1 & 73 & 0,001449 & $\mathrm{X}$ \\
\hline & 101 & 0,002706 & $\mathrm{Y}$ \\
\hline Dasar & 356 & - & $\mathrm{X}$ \\
\hline & 356 & - & $\mathrm{Y}$ \\
\hline
\end{tabular}

\section{Kinerja Batas Layan Struktur Gedung}

Untuk memenuhi persyaratan kinerja batas layan struktur, dalam segala hal simpangan antar tingkat yang dihitung dari simpangan struktur gedung tidak boleh melampaui $0,03 / \mathrm{R}$ $\mathrm{x}$ tinggi tingkat yang bersangkutan atau $30 \mathrm{~mm}$, tergantung mana yang nilainya lebih kecil seperti persamaan dibawah ini :

$\Delta$ s antar tingkat $<0,03 / \mathrm{R} \times \mathrm{h}$ (SNI 03-17262002)

Tabel 3. Kinerja Batas Layan Struktur Gedung Arah X

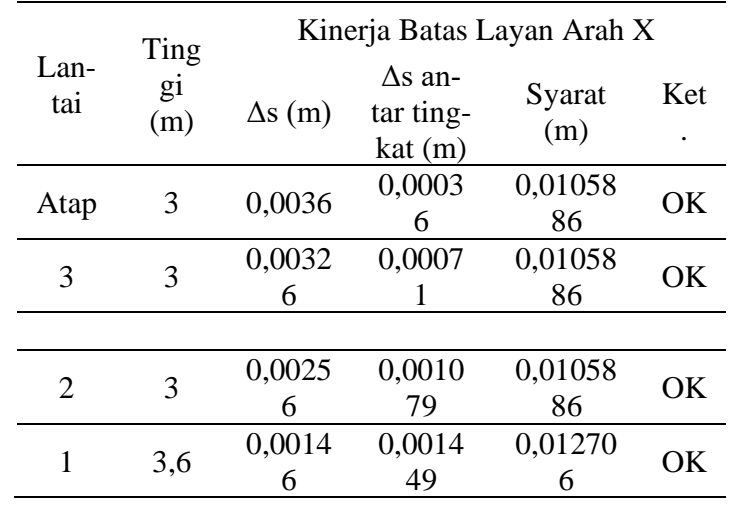




$$
\text { Dasa }
$$$$
r
$$

Tabel 4. Kinerja Batas Layan Struktur Gedung Arah Y

\begin{tabular}{cccccc}
\hline $\begin{array}{c}\text { Lan- } \\
\text { tai }\end{array}$ & $\begin{array}{c}\text { Ting } \\
\text { gi } \\
(\mathrm{m})\end{array}$ & $\begin{array}{c}\Delta \mathrm{s} \\
(\mathrm{m})\end{array}$ & $\begin{array}{c}\Delta \text { s antar } \\
\text { tingkat } \\
(\mathrm{m})\end{array}$ & $\begin{array}{c}\text { Syarat } \\
(\mathrm{m})\end{array}$ & Ket \\
\hline Atap & 3 & $\begin{array}{c}0,007 \\
5\end{array}$ & $\begin{array}{c}0,00097 \\
9\end{array}$ & $\begin{array}{c}0,010588 \\
2\end{array}$ & OK \\
\hline 3 & 3 & $\begin{array}{c}0,006 \\
5\end{array}$ & $\begin{array}{c}0,00155 \\
6\end{array}$ & $\begin{array}{c}0,010588 \\
2\end{array}$ & OK \\
\hline 2 & 3 & $\begin{array}{c}0,005 \\
0\end{array}$ & 0,00228 & $\begin{array}{c}0,010588 \\
2\end{array}$ & OK \\
\hline 1 & 3,6 & $\begin{array}{c}0,002 \\
8\end{array}$ & $\begin{array}{c}0,00270 \\
6\end{array}$ & 0,012706 & OK \\
\hline Dasa & 0 & 0 & 0 & 0 & - \\
\hline $\mathrm{r}$ & & & & &
\end{tabular}

\section{Kinerja Batas Ultimate Struktur Gedung}

Kinerja Batas Ultimate Arah X

$\Delta$ s lt. 3 - lt. $2=0,003238-0,002528$

$$
\begin{aligned}
& =\quad 0,00071 \\
& \zeta \times \Delta s \quad<\quad 0,02 \times 3 \\
& 5,949999895 \times 0,00071<0,02 \times 3 \\
& 0,0042245 \mathrm{~m}<0,06 \mathrm{~m}
\end{aligned}
$$

Kinerja Batas Ultimate Arah Y

$$
\begin{array}{cl}
\Delta \text { s 1t. } 3 \text { - lt. } 2= & 0,006542-0,004986 \\
& =0,001556 \\
\zeta \mathrm{x} \Delta \mathrm{s} & <0,02 \times \mathrm{h} \\
5,95 \times 0,001556 & <0,02 \times 3 \\
0,0092582 \mathrm{~m} & <0,06 \mathrm{~m} \\
\text { (Memenuhi syarat ) } &
\end{array}
$$

\section{Analisis Hubungan Balok Kolom Tengah Bentang}

a. Jumlah tulangan yang mengalami tekan (-), 2-D19 (567 mm)

$$
\begin{aligned}
\mathrm{a} & =\operatorname{Ag} \times 1,25 \times \text { fy } / 0,85 \times \text { f'c } \times \mathrm{b} \\
& =567 \times 1,25 \times 400 / 0,85 \times 33,2 \times 300 \\
& =283385 / 8466 \\
& =33,473 \\
\mathrm{Mn}- & =\text { As } \times \text { fy } \times(\mathrm{d}-\mathrm{a} / 2) \\
& =567 \times 400 \times(450-33,473 / 2) \\
& =98224266,987 \quad \mathrm{Nmm} \\
& =98,22426699 \quad \mathrm{KNmm}
\end{aligned}
$$

b. Jumlah tulangan yang mengalami tarik

$$
\begin{aligned}
(+), 4-D 19(1134 \mathrm{~mm}) & \\
\mathrm{a} & =\mathrm{Ag} \times 1,25 \times \mathrm{fy} / 0,85 \times \mathrm{f} ' \mathrm{c} \times \mathrm{b} \\
& =1134 \times 1,25 \times 400 / 0,85 \times 33,2 \times 300 \\
& =566770 / 8466 \\
& =66,947 \\
\mathrm{Mn}+ & =\text { As } \times \text { fy } \times(\mathrm{d}-\mathrm{a} / 2) \\
& =1134 \times 400 \times(450-66,947 / 2)
\end{aligned}
$$

$$
\begin{aligned}
& =188859867,9 \quad \mathrm{Nmm} \\
& =188,8598679 \quad \mathrm{KNmm} \\
& \mathrm{Mu}=(\mathrm{Mn}-+\mathrm{Mn}+) / 2 \\
& =(98,22426699+188,8599) / 2 \\
& =287,0841349 / 2 \\
& =143,542 \mathrm{KNmm} \\
& \mathrm{Mu}<\mathrm{Mn} \mathrm{Max} \text { OK } \\
& 143,542<188,8598679 \text { OK } \\
& \mathrm{Vh}=2 \times \mathrm{Mu} / 3,52 \times 2 \\
& =2 \times 143,542 / 1,76 \\
& =287,084 / 1,76 \\
& =163,116 \mathrm{KN} \\
& \text { T1 (10-D19) (2834 mm) } \\
& \mathrm{T} 1=\text { As } \mathrm{x} 1,25 \mathrm{x} \text { fy } \\
& =2834 \times 1,25 \times 400 \\
& =1416924 \mathrm{~N} \\
& =1416,925 \mathrm{KN} \\
& \text { T2 (12-D19) (3401 mm) } \\
& \mathrm{T} 2=\text { As } \mathrm{x} 1,25 \mathrm{x} \text { fy } \\
& =3401 \times 1,25400 \\
& =1700310 \mathrm{~N} \\
& =1700,31 \mathrm{KN} \\
& \text { c. Gaya geser yang terjadi } \\
& \mathrm{V}=\mathrm{T} 1+\mathrm{T} 2-\mathrm{Vh} \\
& =1416,925+1700,31-163,116 \\
& =2954,119014 \quad \mathrm{KN} \\
& =0,75 \times 1,7 \times(450 \times 900) \times \sqrt{33}, 2 \\
& =2975323,893 \quad \mathrm{~N} \\
& =2975,323893 \quad \mathrm{KN} \\
& \phi \mathrm{Vc}>\mathrm{V} \quad \mathrm{OK} \\
& 2975,323893>2954,119014
\end{aligned}
$$

\section{Analisis Hubungan Balok Kolom Ujung \\ Bentang}

a. Jumlah tulangan yang mengalami tekan (-), 2-D19 (567 mm)

$$
\begin{aligned}
& \mathrm{a} \quad=\operatorname{Ag} \times 1,25 \times \text { fy } / 0,85 \times \text { f'c } \times \text { b } \\
& =567 \times 1,25 \times 400 / 0,85 \times 33,2 \times 200 \\
& =283385 / 8466 \\
& =33,473 \\
& \text { Mn- }=\text { As x fy x (d-a/2) } \\
& =567 \times 400 \times(450-33,473 / 2) \\
& =98224266,987 \quad \mathrm{Nmm} \\
& =98,224266987 \quad \mathrm{KNmm} \\
& \mathrm{Mu}=(\mathrm{Mn}-) / 2 \\
& =(98,224266987) / 2 \\
& =49,11213349 \quad \mathrm{KNmm} \\
& \mathrm{Mu}<\mathrm{MnMax} \text { OK } \\
& 49,11213349<98,224266987 \mathrm{OK} \\
& \mathrm{Vh}=2 \times \mathrm{Mu} /(5,4-4) \times 2 \\
& =2 \times 49,11213349 / 0,7
\end{aligned}
$$




$$
=45,36825106 / 0,7
$$$$
=140,3203814 \quad \mathrm{KN}
$$

T1 (12-D19) (3401 mm)

$\mathrm{T} 1=$ As $\mathrm{x} 1,25 \mathrm{x}$ fy

$$
=3401 \times 1,25 \times 400
$$$$
=1700310 \mathrm{~N}
$$$$
=1700,310 \mathrm{KN}
$$

b. Gaya geser yang terjadi

$$
\mathrm{V}=\mathrm{T} 1-\mathrm{Vh}
$$$$
=1700,310-140,3204
$$$$
=1559,989619 \quad \mathrm{KN}
$$

c. Kuat geser Nominal

$\phi \mathrm{Vc}=0,75 \times 1,7 \times \mathrm{Aj} \times \sqrt{ } \mathrm{f}^{\prime} \mathrm{c}$

$=0,75 \times 1,7 \times(450 \times 900) \times \sqrt{ } 33,2$

$=2975323,893 \quad \mathrm{~N}$

$=2975,323893 \quad \mathrm{KN}$

$\phi \mathrm{Vc}>\mathrm{V} \quad \mathrm{OK}$

$2975,323893>1559,989619$

(Sambungan Aman)

\section{SIMPULAN}

Kontrol batas layan didapat hasil untuk arah $\mathrm{x}$ dan y aman terhadap kinerja batas layan, pada $\Delta$ s terjauh yaitu untuk $\Delta$ s Lantai 3 - Lantai 2 arah X 0,00071 mm < 0,09 mm, arah Y $0,001556 \mathrm{~mm}<0,09 \mathrm{~mm}$. Kemudian untuk batas ultimit didapat hasil untuk arah $\mathrm{x}$ dan $\mathrm{y}$ aman terhadap kinerja batas ultimit, pada $\Delta \mathrm{s}$ terjauh yaitu untuk $\Delta$ s Lantai 3 - Lantai 2 arah

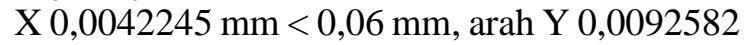
$\mathrm{mm}<0,06 \mathrm{~mm}$. Hasil dari analisis SAP 2000 V14, didapatkan balok yang menerima momen terbesar pada hubungan balok kolom tengah bentang sebagai sample perhitungan analisis hubungan balok kolom yang mewakili seluruh sambungan struktur beton pracetak Rumah Susun Joho, $\phi \mathrm{Vc}>\mathrm{V}$ maka sambungan aman. Untuk balok yang menerima momen terbesar pada hubungan balok kolom tepi bentang sebagai sample perhitungan analisis hubungan balok kolom yang mewakili seluruh sambungan struktur beton pracetak Rumah Susun Joho, $\phi \mathrm{Vc}>\mathrm{V}$ maka sambungan aman.

\section{DAFTAR PUSTAKA}

Chen, W.F., Lui, E.M. 2006. Earthquake Engineering for Structural Design, CRC/Taylor \& Francis. Florida.
Hendrawan Wahyudi, dan Hery Dwi Hanggoro, 2010, Perencanaan Struktur Gedung BPS Provinsi Jawa Tengah Menggunakan Beton Pracetak. Universitas Diponegoro. Program Reguler II Jurusan Teknik Sipil Fakultas Teknik Universitas Diponegoro Semarang. Semarang.

Lazuardi Prihatmojo, M. Taufik Hidayat, dan Siti Nurlina. 2017, Studi Analisis Sambungan Balok-Kolom Dengan Sistem Pracetak Pada Gedung Kampus Fakultas Ilmu Budaya Universitas Brawijaya. Jurusan Teknik Sipil Fakultas Teknik Universitas Brawijaya, Malang.

McNulty, J.F., 1956. Thrust Loading on Piles. Journal Soil Mech. And Foundation, Div. LXXII, ASCE.

Nurjaman, Hari Nugraha., Lutfi Faizal, dan Hasiholan R. Sidjabat. 2010, Perilaku Aktual Bangunan Gedung dengan Sistem Pracetak Terhadap Gempa Kuat. Seminar dan Pameran HAKI-Perkembangan dan KemajuanKonstruksi Indonesia.

Pangestu Kusumawardhana. 2012, Kapasitas Lentur Sambungan Balok Pracetak Beton Bertulang. Jurusan Teknik Sipil Fakultas Teknik Universitas Sebelas maret Surakarta, Surakarta.

Schodek, Daniel L. 1999. Struktur Edisi kedua. Jakarta: Erlangga.

SNI 03-1726-2002. 2002. Standar Perencanaan Ketahanan Gempa untuk Struktur Bangunan Gedung. Jakarta: Badan Standarisasi Nasional.

SNI 03-1727-1989. 2002. Pedoman Perencanaan Pembebanan untuk Rumah dan Gedung. Jakarta: Badan Standarisasi Nasional.

SNI 03-2847-2002. 2002. Tata Cara Perhitungan Beton untuk Bangunan Gedung. Jakarta: Badan Standarisasi Nasional.

Wibowo, Fx. Nurwadji. 2006, Sambungan Pada Rangka Batang Beton Pracetak. Jurnal Teknik Sipil 7 (Oktober) : 80-96. 